\title{
Fixed bed dynamics of single and multicomponent adsorption of pentane and hexane isomers in ZIF-8
}

\author{
Adriano Henrique $^{\mathrm{a}, \mathrm{b}, \mathrm{c}, *}$, Alírio E. Rodrigues ${ }^{\mathrm{a}}$, José A.C. Silva ${ }^{\mathrm{b}, \mathrm{c}, *}$ \\ ${ }^{a}$ Laboratory of Separation and Reaction Engineering - Laboratory of Catalysis and Materials (LSRE/LCM), Department of Chemical Engineering, Faculty of Engineering, \\ University of Porto, Rua Dr. Roberto Frias, S/N, 4200-465 Porto, Portugal \\ ${ }^{\mathrm{b}}$ Laboratory of Separation and Reaction Engineering (LSRE), Associate Laboratory LSRE/LCM, Department of Chemical and Biological Technology, Polytechnic Institute of \\ Bragança, Campus de Santa Apolónia, 5300-857 Bragança, Portugal \\ ' Centro de Investigação de Montanha (CIMO), Instituto Politécnico de Bragança, Campus de Santa Apolónia, 5300-253 Bragança, Portugal
}

\section{A R T I C L E I N F O}

\section{Keywords:}

Pentane/hexane isomers

MOF ZIF-8

Fixed bed adsorption

Breakthrough curves

Numerical Modelling

\begin{abstract}
A B S T R A C T
Single, quinary and septenary fixed bed breakthrough experiments of pentane (nC5/iC5) and hexane (nC6/2MP/ $3 \mathrm{MP} / 23 \mathrm{DMB} / 22 \mathrm{DMB}$ ) isomers were performed in shaped zeolitic imidazolate metal organic framework ZIF-8. Adsorption equilibrium isotherms for linear nC5 and nC6 were measured from the single component breakthrough curves covering the temperature range between 373 and $473 \mathrm{~K}$ and partial pressures up to $50 \mathrm{kPa}$. The equimolar septenary (nC5/iC5/nC6/2MP/3MP/23DMB/22DMB) and quinary (iC5/2MP/3MP/23DMB/22DMB) studies were performed at the same temperature range and total hydrocarbon pressure of $25 \mathrm{kPa}$. In the septenary experiments the following sorption hierarchy was observed: nC6 $>$ nC5 $>2 \mathrm{MP}>3 \mathrm{MP}>\mathrm{iC5}>23 \mathrm{DMB}>2$ DMB. Results also show that the sorption of the linear nC5 and nC6 is dominated by equilibrium in contrast with the sorption of branched isomers which is kinetically controlled. The quinary experiments with $\mathrm{C} 5 / \mathrm{C} 6$ branched paraffins evidences the partially separation by classes of mono- and di-branched isomers. The equilibrium data were modelled by the Sips isotherm and the fitted parameters were used to simulate the breakthrough data through a mathematical model developed in a Matlab code using the method of lines (MOL). In the numerical simulations equal diffusivities constants $\left(\mathrm{D}_{\mathrm{c}} / \mathrm{r}_{\mathrm{c}}{ }^{2}\right)$ for linear $\mathrm{nC} 5 / \mathrm{nC} 6$ were used, being it $0.002 \mathrm{~s}^{-1}$ at $373 \mathrm{~K}$, which is a value 100 times higher than its respective value for the mono-branched isomers iC5, 2MP and 3MP, and 300 times higher than for the di-branched hexane isomer 22DMB. It is also shown the effect of the residence time of the gas regarding the fixed bed separation of the pentane and hexane isomers, from where it is clear that increasing the residence time improves the separation between the compounds.
\end{abstract}

\section{Introduction}

The gasoline is the most common type of fuel used in automotive cars today. The behavior of its combustion is evaluated by the research octane number (RON) which is a measure of its knock resistance $[1,2]$. Knocking is a sharp, pinging sound, resulting from the spontaneous combustion of the air-fuel mixture in the cylinder while the fuel is being compressed. The resulting knocking increases the risk of engine damage and decreases the engine efficiency. When the RON is high, the combustion occurs as a smooth explosion instead a self-ignite and detonation, improving the performance of the vehicle motor [1-4].

Since European legislation has imposed restrictions on gasoline to reduce the concentration of additives, such as aromatic and olefins compounds, due to their impacts on the environmental and human health, the petrochemical industry has been searching to find alternatives to enhance the required RON in the gasoline [5]. Therefore, the process of isomerization, to improve the quality of light straight run naphtha (LSRN), has gaining significant attention. This process transforms straight chain paraffins into their branched isomers with higher RON content in a fixed bed reactor using a catalyst. The linear pentane (nC5, RON: 61.8) is isomerized to produce isopentane (iC5, RON: 92.3), while the isomerization of normal hexane (nC6, RON:24) produces the mono-branched 2-methylpentane (2MP, RON: 73.4) and 3-methylpentane (3MP, RON: 74.5) isomers, and di-substituted paraffins 2,3-dimethylbutane (23DMB, RON: 101.7) and 2,2-dimethylbutane (22DMB, RON: 91.8) isomers [6-8].

Unfortunately, the isomerization process is a thermodynamic limited reaction and the isomerate mixture produced still contains linear

\footnotetext{
* Corresponding authors.

E-mail addresses: adriano_henrique@ipb.pt (A. Henrique), jsilva@ipb.pt (J.A.C. Silva).
} 


\begin{tabular}{|c|c|c|c|}
\hline \multicolumn{2}{|c|}{ Nomenclature } & \multirow{2}{*}{$\begin{array}{l}q_{\text {exp }, i} \\
q_{\text {Sips }, i} \\
q^{*}\end{array}$} & \multirow{2}{*}{$\begin{array}{l}\text { experimental loading }\left(\mathrm{mol} \cdot \mathrm{kg}^{-1}\right) \\
\text { loading predicted by Sips model }\left(\mathrm{mol} \cdot \mathrm{kg}^{-1}\right) \\
\text { adsorbed phase concentration at equilibrium conditions } \\
\left(\mathrm{mol} \cdot \mathrm{kg}^{-1}\right)\end{array}$} \\
\hline $\begin{array}{l}a_{c} \\
a_{n}\end{array}$ & $\begin{array}{l}\text { specific area of the column }\left(\mathrm{m}^{-1}\right) \\
\text { specific area of the solid }\left(\mathrm{m}^{-1}\right)\end{array}$ & & \\
\hline$b_{i}$ & adsorption equilibrium affinity constant $\left(\mathrm{MPa}^{-1}\right)$ & $\bar{q}_{i}$ & average loading in the solid phase $\left(\mathrm{mol} \cdot \mathrm{kg}^{-1}\right)$ \\
\hline$C_{0, i}$ & gas phase concentration at the inlet of the bed $\left(\mathrm{mol} \cdot \mathrm{m}^{-3}\right)$ & $q_{\max }$ & maximum saturation loading $\left(\mathrm{mol} \cdot \mathrm{kg}^{-1}\right)$ \\
\hline$C_{t}$ & total gas concentration in bulk phase $\left(\mathrm{mol} \cdot \mathrm{m}^{-3}\right)$ & & ideal gas constant $\left(\mathrm{J} \cdot \mathrm{mol}^{-1} \cdot \mathrm{K}^{-1}\right)$ \\
\hline$c_{p g}$ & heat capacity of gas phase $\left(\mathrm{J} \cdot \mathrm{mol}^{-1} \cdot \mathrm{K}^{-1}\right)$ & $T_{0}$ & reference temperature $(\mathrm{K})$ \\
\hline$c_{p s}$ & heat capacity of solid adsorbent $\left(\mathrm{J} \cdot \mathrm{mol}^{-1} \cdot \mathrm{K}^{-1}\right)$ & $T$ & temperature in bulk gas phase $(\mathrm{K})$ \\
\hline$D_{a x}$ & axial dispersion coefficient $\left(\mathrm{m}^{2} \cdot \mathrm{s}^{-1}\right)$ & $T_{f}$ & temperature in bulk gas phase at inlet of column $(\mathrm{K})$ \\
\hline$D_{c}$ & $\begin{array}{l}\text { diffusion coefficient of solutes in the porous of the ad- } \\
\text { sorbents }\left(\mathrm{m}^{2} \cdot \mathrm{s}^{-1}\right)\end{array}$ & $\begin{array}{l}T_{s} \\
T_{w}\end{array}$ & $\begin{array}{l}\text { temperature of solid phase }(\mathrm{K}) \\
\text { temperature of the column wall }(\mathrm{K})\end{array}$ \\
\hline$E_{D i}$ & activation energy for diffusivity $\left(\mathrm{kJ} \cdot \mathrm{mol}^{-1}\right)$ & $t_{r t}$ & retention time (min) \\
\hline$F_{i}$ & $\begin{array}{l}\text { molar flowrate of adsorbate species in the bulk gas phase } \\
\left(\mu \mathrm{mol} \cdot \mathrm{s}^{-1}\right)\end{array}$ & & $\begin{array}{l}\text { superficial velocity }\left(\mathrm{m} \cdot \mathrm{s}^{-1}\right) \\
\text { interstitial velocity }\left(\mathrm{m} \cdot \mathrm{s}^{-1}\right)\end{array}$ \\
\hline$h_{f}$ & $\begin{array}{l}\text { film heat transfer coefficient between gas and solid phase } \\
\left(\mathrm{W} \cdot \mathrm{m}^{-2} \cdot \mathrm{K}^{-1}\right)\end{array}$ & & $\begin{array}{l}\text { molar fraction of adsorbate species in bulk phase }(-) \\
\text { distance coordinate along fixed bed (m) }\end{array}$ \\
\hline$h_{w}$ & $\begin{array}{l}\text { overall heat transfer coefficient at the wall of the column } \\
\left(\mathrm{W} \cdot \mathrm{m}^{-2} \cdot \mathrm{K}^{-1} \text { ) }\right. \\
\text { axial bed thermal conductivity }\left(\mathrm{W} \cdot \mathrm{m}^{-1} \cdot \mathrm{K}^{-1} \text { ) }\right.\end{array}$ & Gree & \\
\hline $\begin{array}{l}k_{\text {ax }} \\
k_{L D F} \\
L\end{array}$ & $\begin{array}{l}\text { linear driving force mass transfer coefficient }\left(\mathrm{s}^{-1}\right) \\
\text { column length }(\mathrm{m})\end{array}$ & $\alpha$ & $\begin{array}{l}\text { constant parameter for the temperature dependence of the } \\
\text { heterogeneity index }(-)\end{array}$ \\
\hline$m_{a d s}$ & mass of adsorbent in the bed $(\mathrm{kg})$ & $\varepsilon_{b}$ & packed bed porosity $(-)$ \\
\hline$N$ & total number of experiments $(-)$ & $\rho_{a}$ & apparent adsorbent density $\left(\mathrm{kg} \cdot \mathrm{m}^{-3}\right)$ \\
\hline$n c p$ & number of components $(-)$ & $\rho_{b}$ & bulk density of solid $\left(\mathrm{kg} \cdot \mathrm{m}^{-3}\right)$ \\
\hline$n_{i, 0}$ & heterogeneity index at the reference temperature (-) & $\tau_{f b}$ & $L / v$ residence time in the fixed bed (s) \\
\hline$n_{i}$ & heterogeneity index (-) & $\Delta H_{i}$ & heat of adsorption $\left(\mathrm{kJ} \cdot \mathrm{mol}^{-1}\right)$ \\
\hline $\mathrm{p}$ & partial pressure $(\mathrm{kPa})$ & & \\
\hline $\mathrm{p}_{\text {TC6 }}$ & hydrocarbon total pressure $(\mathrm{kPa})$ & & \\
\hline
\end{tabular}

(nC5 and nC6) and mono-branched (2MP and 3MP) paraffins unreacted, meaning that the final output stream of the isomerization reactor needs to be further treated to separate the isomerate product in a high and low octane fraction. Nowadays, the technologies Total Isomerization Process (TIP) from Universal Oil Products (UOP) [9-11] and the Ipsorb and Hexorb processes from Axens [12-14] performs the separation of low RON linear paraffins nC5 and nC6 from its branched isomers, after the isomerization step, by adsorption processes via kinetic mechanisms employing zeolite $5 \mathrm{~A}$. However, this adsorbent is not able to separate mono-branched (2MP and 3MP) from di-branched (23DMB and 22DMB) paraffins, and the presence of mono-branched hexanes (moderate RON) in the final isomerate product contribute to decrease the performance of the process.

The adsorption separation of C5/C6 fractions has been deeply studied by scholars. Among these researches, a wide variety of zeolites are mentioned as candidates to improve the performance of these processes, such as SAPO-5, AlPO-5, SSZ-24, MCM-22, zeolite beta, among others [15-21]. Besides zeolites, the newest class of porous material, the metal-organic frameworks have gained attention for this purpose and between them, the zinc methyl-imidazolate ZIF-8 [22] is of particular interest, due to its chemical and thermal stability and principally for presenting higher adsorption capacity than zeolite 5A [23].

There are several papers on literature addressing the separation of light naphtha in ZIF-8, which have reported the adsorption equilibrium and properties of pentane [24,25] and hexane isomers [23,26-33]. Among them, Zhang et al [25] reported a complete separation of linear nC5 from the branched iC5 from binary breakthrough experiments. Recently, Henrique et al [33] showed (also through competitive breakthrough experiments) that ZIF-8 has the ability to separate the linear nC6 from its branched isomers (equilibrium based) and partially separate mono- from di-branched isomers (via a kinetic mechanism). However, there is no experimental work on literature addressing the sorption of mixtures of pentane and hexane isomers in ZIF-8 which are present in TIP process.
Thus, in view of a design and optimization of cyclic adsorption processes for the octane improvement of gasoline, the goal of the present work is to study the adsorption behavior pentane/hexane isomers mixtures in a fixed bed containing ZIF-8, measuring simultaneously single, quinary and septenary breakthrough curves and analyzing the effect of temperature, total hydrocarbon pressure and residence time of the gas in the bed. Additionally, from the experimental data adsorption isotherms are collected and modeled by the Sips isotherm. Finally, a fixed bed adsorption mathematical model is developed, in Matlab code, to qualitatively predict the experimental breakthrough curves of $\mathrm{C5} / \mathrm{C6}$ isomers in ZIF-8, to be used later in the simulation of a cyclic adsorption process.

\section{Experimental section}

\subsection{ZIF-8 and paraffins isomers}

The ZIF-8 studied in this work was provided by TU Dresden, Materials Center. It is in shaped form with an average particle size of $2 \mathrm{~mm}$ (more details can be found at http://www.metalorganicframeworks.eu/pdf/adsorbentien/zif8.pdf). The pentane (nC5/ iC5) and hexane isomers (nC6/2MP/3MP/23DMB/22DMB) are of analytical grade supplied by Sigma Aldrich with $99+\%$ of purity.

\subsection{Adsorption equilibrium apparatus}

The experimental data were measured in an apparatus developed at LSRE-LCM (Polytechnic Institute of Bragança) to measure single and multicomponent breakthrough curves in a fixed bed (dynamic system), for which, Fig. 1 shows its schematic diagram. The experimental set-up consists of three main sections: (i) a gas preparation section, (ii) an adsorption section, and (iii) an analytical section. In the gas preparation section, the paraffins (liquid phase) are continuously introduced with a syringe pump in the preparative chromatograph and mixed with the 


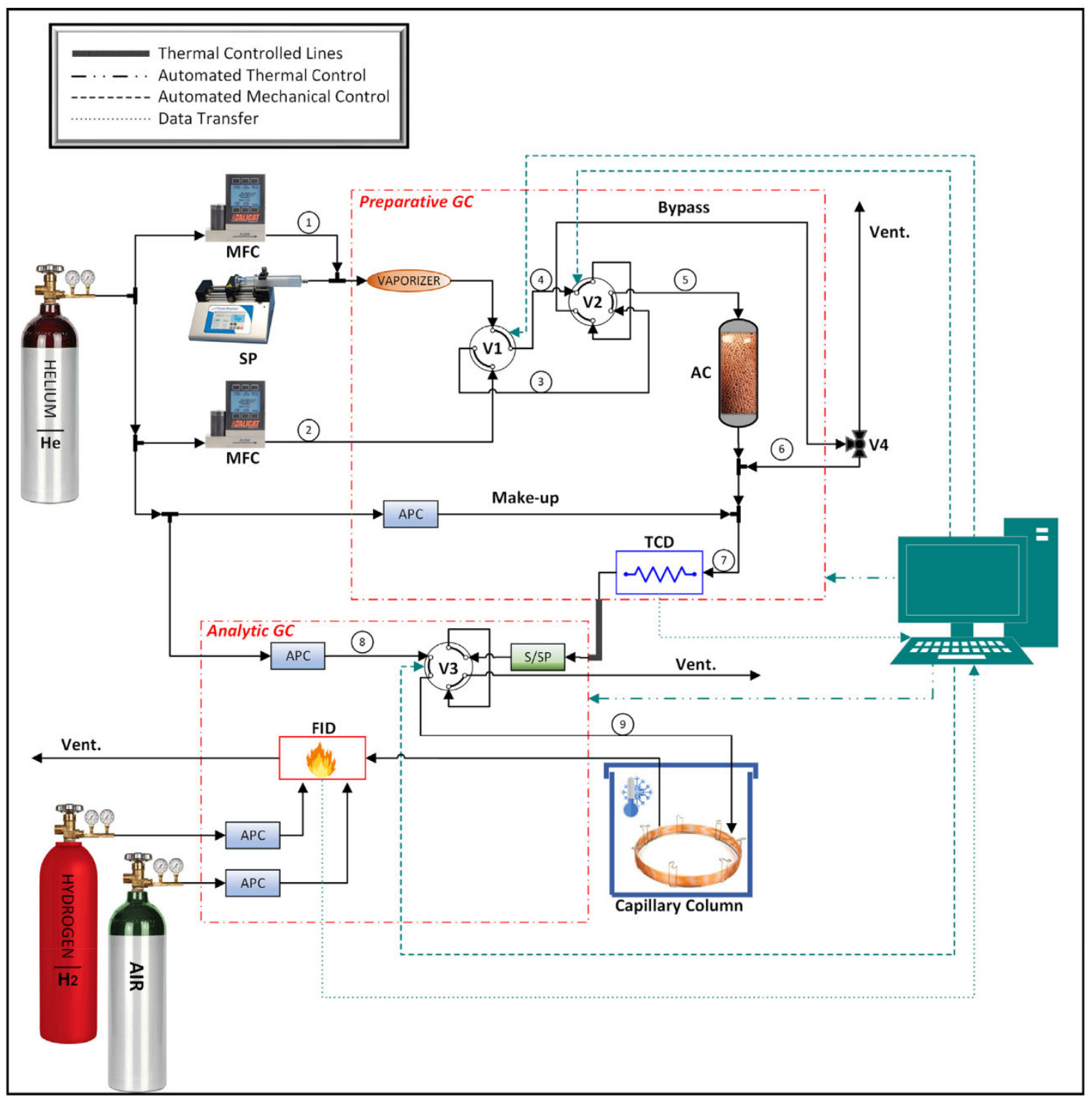

Fig. 1. Schematic diagram of the experimental set-up used to measure adsorption equilibrium data: (MFC) mass flow controller; (SP) syringe pump; (AC) adsorption column; (APC) advanced pneumatic control; (S/SP) split/splitless-injector; (TCD) thermal conductivity detector; (FID) flame ionization detector; (V1) 4-way valve; (V2) and (V3) 6-way valve; (V4) 3-way valve, (1(2)(3)(36(3)(8) streams.

carrier gas (helium), monitored by a mass flow controller (MFC), to run through the vaporizer. A stainless steel column with $0.12 \mathrm{~m}$ long and $0.01 \mathrm{~m}$ internal diameter, is entirely filled with the adsorbent material and placed inside the preparative chromatograph oven. The last part is the analytical section, is composed by an analytical chromatograph, a capillary GC column coating (Supelco with a $15 \mathrm{~m}$ length, $0.1 \mathrm{~mm}$ outside diameter and $0.1 \mu \mathrm{m}$ poly(dimethyl sulfoxane) immersed in an ice water bath [29], and a Flame Ionization Detector (FID). Detailed information about the experimental apparatus has been reported elsewhere [33].

\subsection{Experimental procedure}

The experimental procedure to obtain breakthrough curves consists in continuously measuring the concentration profile of the hydrocarbon species as a function of time at the outlet of the adsorption column, which is kept at a constant temperature. A more detailed description about the experimental procedure and also the determination of equilibrium loadings can be found elsewhere [33].

\section{Theory}

\subsection{Sips model isotherm}

The Sips isotherm [34,35] is a combination of the Langmuir [36] and Freundlich [37] isotherms and is given by the following equation:

$q_{S i p s, i}=q_{\max , i} \frac{\left(b_{i} p_{i}\right)^{\frac{1}{n_{i}}}}{1+\sum_{k=1}^{j}\left(b_{k} p_{k}\right)^{\frac{1}{n_{k}}}}$

where $q_{\text {Sips }, i}$ is the loading at equilibrium conditions, $q_{\max , i}$ is the maximum saturation loading, $b_{i}$ is the adsorption equilibrium affinity constant, $p_{i}$ is the hydrocarbon partial pressure and $n_{i}$ describes the surface heterogeneity. The index $i$ and $j$ refers to the component and to the number of components present in the mixture, respectively.

The temperature dependence of the equilibrium affinity constant [38] and the heterogeneity index [38] are calculated according to the following equations, respectively: 
$b_{i}=b_{i 0} \exp \left[\frac{-\Delta H_{i}}{R T_{0}}\left(\frac{T_{0}}{T}-1\right)\right]$

$\frac{1}{n_{i}}=\frac{1}{n_{i 0}}+\alpha_{i}\left(1-\frac{T_{0}}{T}\right)$

where $b_{i 0}$ and $n_{i 0}$ is the equilibrium affinity constant and the heterogeneity index at the reference temperature $T_{0}, \Delta H_{i}$ is the adsorption heat, $R$ is the universal gas constant, $T$ is the temperature and $\alpha_{i}$ is a constant parameter.

The experimental data were modeled using an optimization method in order to minimize the mean relative deviations $(\bar{\Delta} q)$ given by the equation:

$\bar{\Delta} q=\frac{1}{N} \sqrt{\sum_{i=1}^{N}\left(\frac{q_{\text {exp }, i}-q_{\text {Sips }, i}}{q_{\text {exp }, i}}\right)^{2}}$

where $\mathrm{N}$ is the number of experimental data measurements.

\subsection{Numerical modeling of equilibrium data}

Table 1 summarizes the mathematical equations used to simulate the adsorption dynamics behavior of pentane and hexane isomers in ZIF-8. The mass transfer from the bulk gas phase to the adsorbent is accounted by the linear driving force model (LDF), which has been used in previous studies $[23,33]$. The numerical solution of the coupled system of partial differential equations was obtained through a Matlab code, by the method of lines (MOL) [39], being the partial differential equations algebraically reduced to a set of ordinary differential equations (ODÉs) by finite differences, using the library of dss routines [39], including approximations from 2nd order to 10th order [40]. Thereafter, the resulting system of ODÉs was integrated by the stiff integrator ode15s available in Matlab. We found in this work that the combination of the MOL routines provided by Schiesser [40] to reduce the PDÉs to ODÉs and solve then in a Matlab code environment was very efficient. Generally, the solution of a seven component breakthrough curve takes about $120 \mathrm{~s}$ of computational time.

\section{Results and discussion}

\subsection{Single component breakthrough experiments}

The single component breakthrough curves of linear nC5 and nC6 were measured at three different temperatures 373,423 , and $473 \mathrm{~K}$, and partial pressure up to $50 \mathrm{kPa}$. Helium is used to setup a total pressure in the column of $101.3 \mathrm{kPa}$. Complete information on the experimental runs performed, including flowrate, mass of adsorbent, loadings (amount adsorbed) and residence time of the gas in the bed, are summarized in Table 2. For single component experiments, the mean retention time obtained from a mass balance over the column can be estimated approximately by [41]: $t_{r t}=\left(\frac{L \varepsilon_{b}}{v_{s}}\right)\left(1+\frac{\rho_{b} q_{i 0}}{\varepsilon_{b} C_{i 0}}\right)$

where, $L$ is the column length, $\varepsilon_{b}$ is the bed porosity, $v_{s}$ is the superficial velocity, $\rho_{b}$ is the bulk density of solid, $q_{, i 0}$ is the loading $\mathrm{pf}$ species $i$ at equilibrium conditions and $C_{i 0}$ is the feed gas phase concentration of species $i$ at the inlet of the bed.

Figs. 2 and 3 (panels a, b, c, d, and e) shows the single component breakthrough curves of the linear compounds nC5 and nC6 in ZIF-8, respectively, plotted in terms of normalized molar flow rate $F_{i} / F_{i 0}$ as a function of time. Its respective mean retention time calculated from Eq. (10) is also indicated in the figures. The loadings calculated from each breakthrough curve (see Table 2) were plotted as a function of the partial pressure in Fig. 4 (panels a and b), given rise to the adsorption equilibrium isotherms for the linear paraffins nC5 and nC6, respectively. In the range of experimental conditions considered, at 373 and $423 \mathrm{~K}$ the isotherms are marked type I accordingly to IUPAC classification [42], while at $473 \mathrm{~K}$ they are practically linear, especially for the linear nC5.

Figs. 2 and 3 shows that for both components (especially at the lowest temperature $373 \mathrm{~K}$ (blue curves)) a clear change in the shape of the breakthrough concentration profiles with increasing the hydrocarbon partial pressure (high feed concentration) is observed, where the breakthrough curves become steeper, due to the effect of the favorable nature of the adsorption isotherm (approaching a rectangular form (Fig. 4)). It is also observed in Figs. 2 and 3 a slow approach to saturation, which can be explained by some heat effects in the fixed bed. At the highest temperature, $473 \mathrm{~K}$ (pink curves), the breakthroughs spread along the axis of time becoming more dispersed (wide mass transfer zone). This is due to the fact that the isotherm approaches a linear shape at this temperature being the fixed bed dynamics dominated by mass transfer resistances and axial dispersion in the bed (see Fig. 4).

The effect of the hydrocarbon partial pressure over the mean retention time is also indicated in Figs. 2 and 3. For instance, considering the linear $\mathrm{nC5}$, for the same temperature $(373 \mathrm{~K})$, when its feed concentration is lower, a longer time is required to reach the saturation of the adsorption column, being approximately $136 \mathrm{~min}$ at $11.1 \mathrm{kPa}$ compared to $48 \mathrm{~min}$ at $53.0 \mathrm{kPa}$. This can be explained from Eq. (10) where the ratio $q_{i 0} / C_{i 0}$ decreases with increasing concentration $C_{i 0}$ in an isotherm approaching a rectangular form since $q_{i 0}$ is practically constant, and consequently the mean retention time decreases.

Also, for the same flowrate and feed concentration the mean retention time decreases significantly as temperature increases, (see Figs. 2 and 3). This is due to the exothermic nature of adsorption equilibrium where the amount adsorbed decrease as the temperature increase. The same trends are also observed for the linear nC6.

Table 1

Mathematical model equations to predict breakthrough curves in a fixed bed adsorption column of ZIF-8.

\begin{tabular}{|c|c|c|}
\hline Fixed bed Adsorption & Equations & \\
\hline Overall mass balance & $\frac{\partial F}{\partial z}+\varepsilon_{b} \frac{\partial C_{t}}{\partial t}+\left(1-\varepsilon_{b}\right) \rho_{a} \sum_{l=1}^{n c p} \frac{\partial q_{i}}{\partial t}=0$ & (5) \\
\hline Mass balance to sorbate species & $\varepsilon_{b} D_{a x i} \frac{\partial}{\partial z}\left(C_{t} \frac{\partial y_{l}}{\partial z}\right)=\frac{\partial}{\partial z}\left(F y_{l}\right)+\varepsilon_{b} \frac{\partial}{\partial t}\left(C_{t} y_{l}\right)+\left(1-\varepsilon_{b}\right) \rho_{a} \frac{\partial q_{l}}{\partial t}$ & (6) \\
\hline Energy balance: solid phase & $\rho_{a} c_{p s} \frac{\partial T_{s}}{\partial t}=a_{p} h_{p}\left(T-T_{s}\right)+\rho_{a} \sum_{l=1}^{n c p}\left(-\Delta H_{l}\right) \frac{\partial q_{l}}{\partial t}$ & (7) \\
\hline Energy balance: gas phase & $K_{a x} \frac{\partial^{2} T}{\partial z^{2}}=F c_{p g} \frac{\partial T}{\partial z}+\varepsilon_{b} C_{t} c_{p g} \frac{\partial T}{\partial t}+\left(1-\varepsilon_{b}\right) a_{p} h_{f}\left(T-T_{s}\right)+a_{c} h_{w}\left(T-T_{w}\right)$ & (8) \\
\hline Mass transfer rate & $\frac{\partial q_{i}}{\partial t}=k_{L D F}\left(q^{*}-\bar{q}_{i}\right)$ & (9) \\
\hline Sips isotherm model & $q_{S i p s, l}=q_{\max , l} \frac{\left(b_{i} p_{i}\right)^{\frac{1}{n_{l}}}}{1+\sum_{k=1}^{J}\left(b_{k} p_{k}\right)^{\frac{1}{n_{k}}}}$ & (1) \\
\hline
\end{tabular}


Table 2

Experimental conditions for single component breakthrough curves of linear nC5 and nC6 in ZIF-8 and loadings.

\begin{tabular}{|c|c|c|c|c|c|c|c|}
\hline Run & Temperature (K) & $\begin{array}{l}\text { Partial pressure } \\
(\mathrm{kPa})\end{array}$ & $\begin{array}{l}\text { Paraffin flowrate } \\
\left(\mu \mathrm{mol} \cdot \mathrm{s}^{-1}\right)\end{array}$ & $\begin{array}{l}\text { Helium flowrate } \\
\left(\mathrm{nm}^{3} \cdot \mathrm{s}^{-1}\right)\end{array}$ & $\begin{array}{l}\text { Mass of adsorbent } \\
\left(\mathrm{kg} \times 10^{3}\right)\end{array}$ & Loading $\left(\mathrm{mol} \cdot \mathrm{kg}^{-1}\right)$ & $\begin{array}{l}\text { Mean retention time } \\
\text { (min) }\end{array}$ \\
\hline \multicolumn{8}{|l|}{ nC5 } \\
\hline 1_1 & 373 & 11.1 & 0.3040 & 55.2 & 1.705 & 1.45 & 136 \\
\hline $1 \_2$ & 373 & 22.0 & 0.6079 & 49.1 & 1.796 & 2.03 & 101 \\
\hline 133 & 373 & 32.5 & 0.9119 & 42.9 & 1.796 & 2.22 & 73.7 \\
\hline 144 & 373 & 42.9 & 1.216 & 36.8 & 1.796 & 2.34 & 58.5 \\
\hline $1 \_5$ & 373 & 53.0 & 1.520 & 30.7 & 1.796 & 2.39 & 47.9 \\
\hline $1 \_6$ & 423 & 11.1 & 0.3040 & 55.2 & 1.796 & 0.642 & 64.0 \\
\hline 177 & 423 & 22.0 & 0.6079 & 49.1 & 1.796 & 1.06 & 52.7 \\
\hline $1 \_8$ & 423 & 32.5 & 0.9119 & 42.9 & 1.796 & 1.35 & 45.1 \\
\hline 1 & 423 & 42.9 & 1.216 & 36.8 & 1.796 & 1.59 & 39.9 \\
\hline $1 \_10$ & 423 & 53.0 & 1.520 & 30.7 & 1.796 & 1.75 & 35.2 \\
\hline 1_11 & 473 & 11.1 & 0.3040 & 55.2 & 1.796 & 0.231 & 23.4 \\
\hline $1 \_12$ & 473 & 22.0 & 0.6079 & 49.1 & 1.796 & 0.426 & 21.6 \\
\hline $1 \_13$ & 473 & 32.5 & 0.9119 & 42.9 & 1.796 & 0.603 & 20.4 \\
\hline 1_14 & 473 & 42.9 & 1.216 & 36.8 & 1.796 & 0.766 & 19.5 \\
\hline $1 \_15$ & 473 & 53.0 & 1.520 & 30.7 & 1.796 & 0.943 & 19.2 \\
\hline \multicolumn{8}{|l|}{ nC6 } \\
\hline $2 \_1$ & 373 & 10.0 & 0.2700 & 55.2 & 1.705 & 2.15 & 227 \\
\hline $2 \_2$ & 373 & 20.0 & 0.5401 & 49.1 & 1.705 & 2.59 & 137 \\
\hline 23 & 373 & 30.0 & 0.8101 & 42.9 & 1.705 & 2.73 & 96.3 \\
\hline 24 & 373 & 40.0 & 1.080 & 36.8 & 1.705 & 2.79 & 74.0 \\
\hline 25 & 373 & 50.0 & 1.350 & 30.7 & 1.705 & 2.80 & 59.6 \\
\hline 266 & 423 & 10.0 & 0.2700 & 55.2 & 1.705 & 1.06 & 112 \\
\hline 27 & 423 & 20.0 & 0.5401 & 49.1 & 1.796 & 1.75 & 97.7 \\
\hline 28 & 423 & 30.0 & 0.8101 & 42.9 & 1.796 & 1.98 & 74.0 \\
\hline 29 & 423 & 40.0 & 1.080 & 36.8 & 1.705 & 2.18 & 58.0 \\
\hline $2 \_10$ & 423 & 50.0 & 1.350 & 30.7 & 1.705 & 2.21 & 47.1 \\
\hline 2_11 & 473 & 10.0 & 0.2700 & 55.2 & 1.796 & 0.432 & 48.6 \\
\hline $2 \_12$ & 473 & 20.0 & 0.5401 & 49.1 & 1.796 & 0.746 & 42.1 \\
\hline $2 \_13$ & 473 & 30.0 & 0.8101 & 42.9 & 1.796 & 1.07 & 40.3 \\
\hline $2 \_14$ & 473 & 40.0 & 1.080 & 36.8 & 1.796 & 1.25 & 35.4 \\
\hline $2 \_15$ & 473 & 50.0 & 1.350 & 30.7 & 1.796 & 1.41 & 31.9 \\
\hline
\end{tabular}

* STP: Standard temperature and pressure conditions.

\subsection{Multicomponent breakthrough experiments}

Breakthrough experiments with equimolar septenary mixtures of linear and branched $\mathrm{C5} / \mathrm{C} 6$ isomers (nC5/iC5/nC6/2MP/3MP/23DMB/ 22DMB), and equimolar quinary mixtures with $\mathrm{C} 5 / \mathrm{C} 6$ branched isomers (iC5/2MP/3MP/23DMB/22DMB) were performed analyzing the effect of temperature to evaluate the sorption dynamics behavior of these paraffins in ZIF-8. Additionally, breakthrough tests with C5/C6 branched isomers were also performed using different values for the residence time of the flow gas in the bed in order to assess the influence of this parameter on the adsorption and separation of branched paraffins in ZIF-8.

\subsubsection{Septenary experiments (nC5/iC5/nC6/2MP/3MP/23DMB/} 22DMB)

The screening tests considering septenary mixtures of C5/C6 isomers were performed at a total hydrocarbon partial pressure of $25 \mathrm{kPa}$ (using helium to setup a total pressure in the column of $101.3 \mathrm{kPa}$ ) and at the temperatures 373,423 and $473 \mathrm{~K}$. More information on the experimental conditions and loadings obtained for each compound are given in Table 3. The experiments were conducted in order to ensure a residence time in the bed, $\tau_{f b}=L / v$ (where $v$ is the interstitial velocity) of approximately $45 \mathrm{~s}$ at $373 \mathrm{~K}$. In a previous study with C6 isomers in ZIF-8 [33], this residence time ensure a convenient partial separation between the mono-branched (2MP/3MP) and di-branched isomers (22DMB/23DMB), which is the main goal in order to improve the separation between high RON compounds (22DMB/23DMB) and low RON ones (2MP/3MP).

In Table 3, one can read that the mixture loadings are thermodynamically consistent, since at a constant total hydrocarbon pressure $(25 \mathrm{kPa})$ they decrease as the temperature increase. The experimental data clearly show that at $373 \mathrm{~K}$ a significant amount of paraffins isomers can be adsorbed in ZIF-8, it being $1.93 \mathrm{~mol} \cdot \mathrm{kg}^{-1}$. However, with the increasing temperature to $473 \mathrm{~K}$, the total loading decreases to only $0.38 \mathrm{~mol} \mathrm{~kg}^{-1}$ (practically five times lower).

Fig. 5 (panels a, b and c) shows the breakthrough curves obtained at the temperatures of 373,423 and $473 \mathrm{~K}$, respectively. Globally, the data shown in this figure indicate that the sorption hierarchy of C5/C6 mixtures in ZIF 8 is always nC6 $>$ nC5 $>2 \mathrm{MP}>3 \mathrm{MP}>\mathrm{iC5}>$ 23DMB $>22$ DMB. It is also observed at all temperatures a different dynamic behavior of the branched and normal paraffins in ZIF-8. The normal paraffins (nC5 and nC6) elute from the column at a mean retention time different (much higher) than the residence time of the gas in the column, indicating that its sorption is equilibrium based. On the other hand, the C5/C6 branched paraffins start their elution earlier, practically at the residence time of the gas mixture in the column due to strong diffusional limitations. However, the approach to feed concentration of the branched paraffins is different, since the mono-branched ones, $2 \mathrm{MP} / 3 \mathrm{MP} / \mathrm{iC} 5$, shows a wide mass transfer zone, in contrast with the di-branched paraffins 23DMB and 22DMB which rapidly saturate at the early stage of the experiments (narrow mass transfer zone).

Another interesting remark observed in Fig. $5 \mathrm{a}$ is the roll-up of the linear nC5 isomer at the elution time of the nC6 being its concentration almost $50 \%$ higher than the one in the feed of the column. This overshoot is an evidence that strong interactions occur in ZIF-8 due to competitive adsorption with the linear nC6. When the temperature increases (Fig. 5b and c), this overshoot in concentration is significantly reduced, since the interactions occurring inside the material becomes 

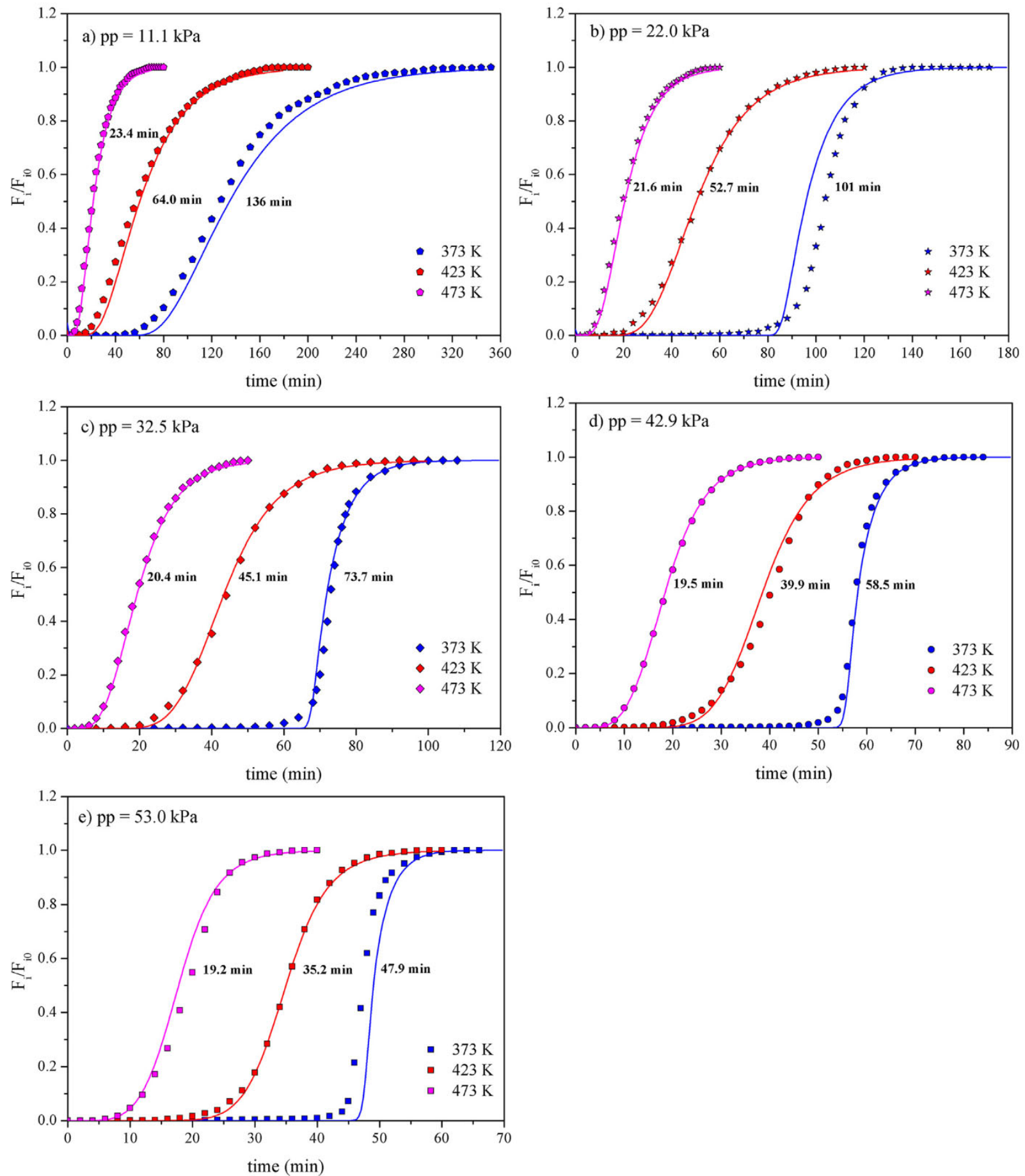

Fig. 2. Experimental and numerical breakthrough curves for adsorption of nC5 in ZIF-8 measured at different partial pressures: (a) $11.1 \mathrm{kPa}$, (b) $22.0 \mathrm{kPa}$, (c) $32.5 \mathrm{kPa}$, (d) $42.9 \mathrm{kPa}$, and (e) $53.0 \mathrm{kPa}$. The continuous lines represent numerical simulations.

smaller.

The ability of ZIF-8 to separate pentanes $[24,25]$ and hexane mixtures [23,26-33] has been studied by several authors separately, but none addressed mixtures of both C5 and C6 isomers. Here, such study shown in Fig. 5a that linear isomers (nC5 and nC6) are completely separated from its branched isomers due to sorption equilibrium, and the mono-branched 2MP, 3MP, and iC5 partially separated from the dibranched ones (23DMB and 22DMB), via a kinetic mechanism due to different diffusional time constants. When the temperature increase in the fixed bed, the degree of separation by classes (linear/mono/di) decreases because the mono-branched fraction becomes to be contaminated by the linear nC5 which elution time decreases, reaching also the inlet concentration (saturation) first than the mono-branched hexane compounds (Fig. 5b and c).

Another important remark that can be retained from these experiments is that the mono-branched isomer isopentane (iC5) has an elution time close to the mono-branched hexanes (2MP and 3MP). The presence of iC5 together with the mono-branched hexane isomers at the outlet of the column represents a drawback in view of the octane improvement of gasoline, since this component has a much higher RON (92.3) than the mono branched 2MP (73.4) and 3MP (74.5). An improved adsorptive pentane/hexane separation process for the octane improvement of gasoline would selectively isolate the most valuable paraffins, 23DMB (RON 101.7), 22DMB (RON 91.8) and iC5 (RON 

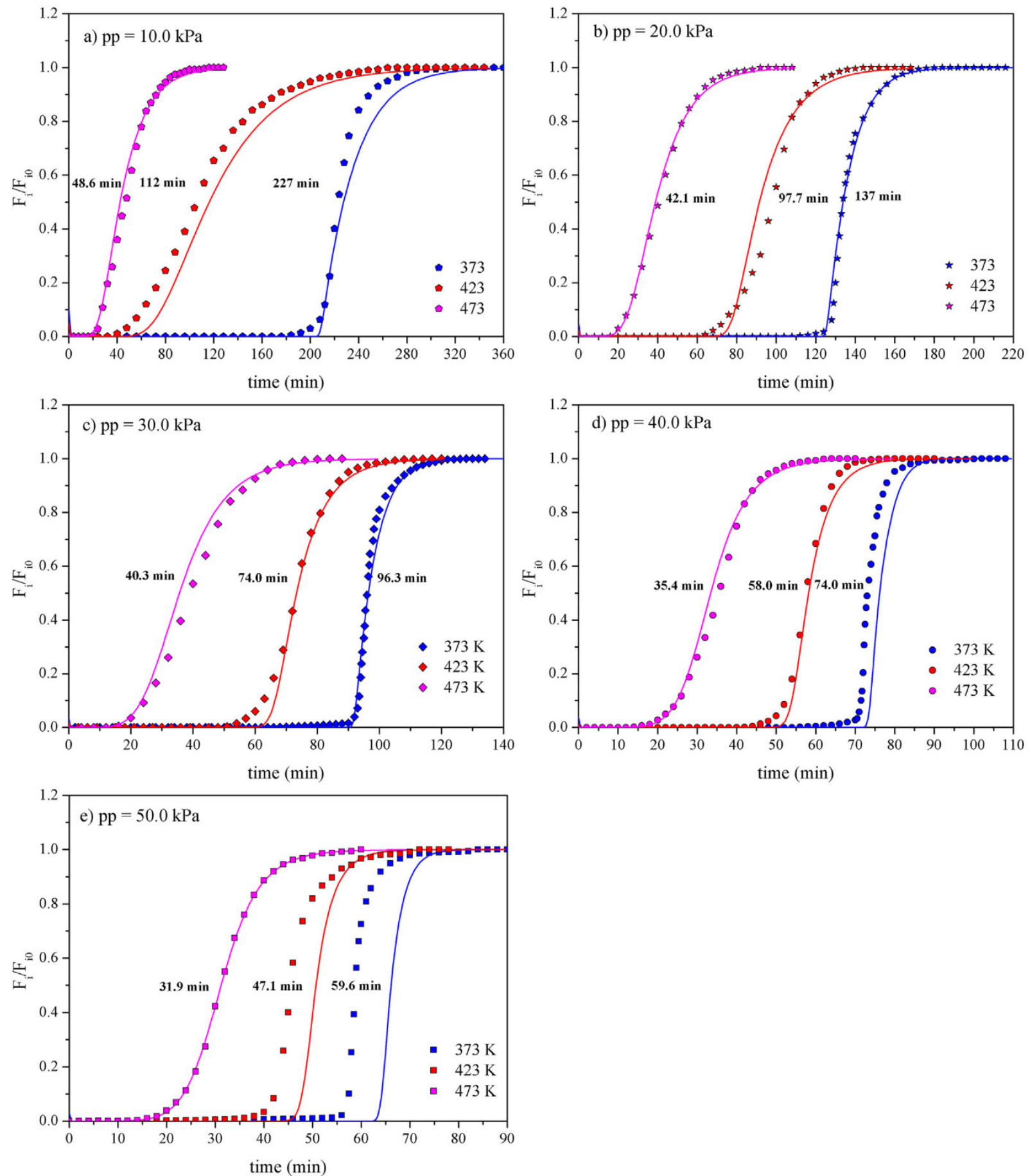

Fig. 3. Experimental and numerical breakthrough curves for adsorption of nC6 in ZIF-8 measured at different partial pressures: (a) $10.0 \mathrm{kPa}$, (b) $20.0 \mathrm{kPa}$, (c) $30.0 \mathrm{kPa}$, (d) $40.0 \mathrm{kPa}$, and (e) $50.0 \mathrm{kPa}$. The continuous lines represent numerical simulations.

92.3) with higher RON from the other low RON isomers.

\subsubsection{Quinary experiments (iC5/2MP/3MP/23DMB/22DMB)}

In light of the previous septenary experiments results and in order to check the adsorption behavior of ZIF-8 without the presence of the linear isomers nC5 and nC6, screening tests considering only branched isomers were performed. The breakthrough curves were measured at the same conditions of the septenary experiments being the loadings given in Table 3.

These breakthrough curves shown in Fig. 6 (panels a, b and c) present the same sorption hierarchy observed in Fig. 5, it being 2MP $>$ 3MP $>$ iC5 $>$ 23DMB > 22DMB. Fig. 6 also shows that isn't feasible to obtain a complete separation between mono-branched and di-branched isomers, since both fractions start eluting at the residence time of the mixture in the packed column, which means that the fraction of di-branched isomers will be always contaminated with the mono-branched ones. It can be also concluded that removing the linear nC5 and nC6 doesńt change the sorption behavior of the branched paraffins.

4.2.3. Influence of residence time of the gas on adsorption behavior of branched C5/C6 isomers

Since the adsorption of C5/C6 branched isomers in ZIF-8 is kinetically controlled, the contact time of the gas with the adsorbent in the 

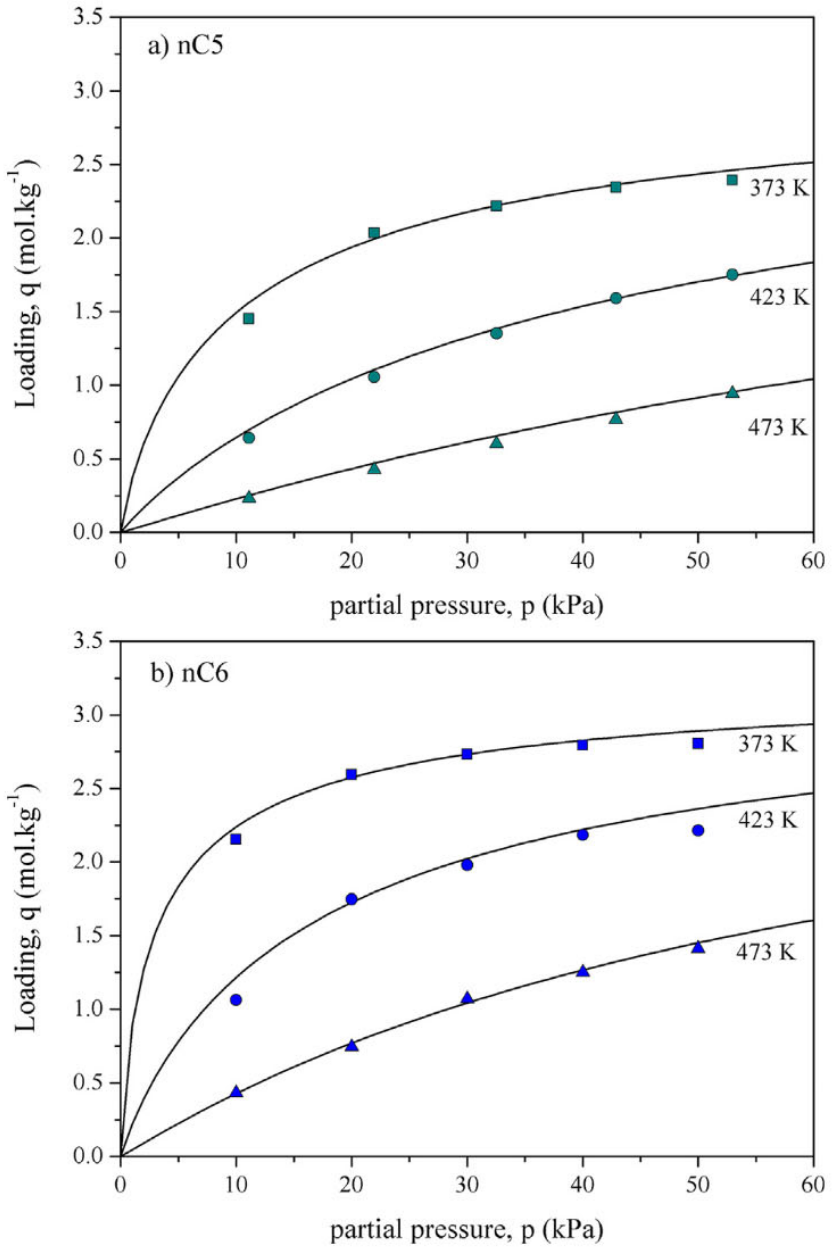

Fig. 4. Adsorption equilibrium isotherms for linear paraffins in ZIF-8: (a) nC5 and (b) nC6. The continuous lines represent the Sips model predictions.

packed column is a parameter of extremely importance that can be exploited for the separation of $\mathrm{C5} / \mathrm{C6}$ isomers. Due to the very slow diffusion of the branched isomers (especially 22DMB and 23DMB), a partial separation between mono- from di-branched isomers can be achieved if this parameter is correctly setup [33]. Thus, in order to analyze this effect, we measured equimolar breakthrough curves of C5/ C6 branched isomers at a fixed total hydrocarbon pressure of $25 \mathrm{kPa}$, temperature of $423 \mathrm{~K}$ at three different residence time of the gas: 22 , 40, and $79 \mathrm{~s}$. The experimental breakthroughs are shown in Fig. 7 (panels a, b and c), respectively, and the experimental conditions and loadings reported on Table 4. For a direct comparison, the breakthrough curves are plotted in terms of the ratio of the normalized molar fraction of each isomer as a function of the molar amount of each isomer fed to the column per unit mass of adsorbent, being the $\times$ axis represented by the Equation (11):

$\frac{t . F_{i}}{m_{a d s}}=\left[\frac{\min \cdot \operatorname{mol} l_{i}}{k g_{a d s} \cdot \min }\right]=\left[\frac{m_{0 l}}{k g_{a d s}}\right]$

Fig. 7 clearly shows that the residence time of the gas changes the sorption dynamics of the branched isomers in ZIF-8. At the lowest residence time of the gas $22 \mathrm{~s}$ (Fig. 7a), 22DMB and 23DMB are practically excluded from the fixed bed since they elute and saturate practically at the residence time. When the residence time increases (Fig. 7b and c) it is clear that apart from starting their elution practically at the residence time their approach to saturation conditions is delayed meaning that they start to become adsorbed in the bed with an increase of the mass transfer zone. For example, at the residence time $79 \mathrm{~s}$ (Fig. 7c) the saturation of 23 DMB is reached only after a feed of $0.4 \mathrm{~mol} \cdot \mathrm{kg}_{\mathrm{ads}}{ }^{-1}$. Similar analysis can be observed for the other compounds. For example, fixing a fed value of $0.2 \mathrm{~mol} \cdot \mathrm{kg}_{\text {ads }}{ }^{-1}$, we can observe that the breakthrough curve shows a concentration of $2 \mathrm{MP}$ that is $60 \%$ of inlet at the residence time $79 \mathrm{~s}$ (Fig. $7 \mathrm{c}$ ) which compares to a value of $80 \%$ at a residence time of $22 \mathrm{~s}$ (Fig. $7 \mathrm{a}$ ).

This behavior results in different loadings as the residence time of the hexane isomers changes in the fixed bed as can be read in Table 4 . Accordingly, the calculated loadings at a residence time of $79 \mathrm{~s}$ for the mono-branched isomers are around 30\% higher than at a residence time of $22 \mathrm{~s}$. Then, one can say that as higher is the contact time, higher is the adsorption of the mono-branched isomers, and higher is the degree of separation between mono from di-branched isomers. It should also be noted, that at the lowest residence time ( $22 \mathrm{~s})$, both di-branched isomers 23DMB and 22DMB were practically excluded from fixed bed.

These results show the great importance of correctly selecting the residence time of linear/branched paraffins in a fixed bed containing ZIF-8, which can result in a complete exclusion of branched paraffins if a very low residence time is setup. This effect has been shown by Mendes et al [23], where spontaneous breakthrough curves were obtained for all branched hexane isomers in a residence time of approximately $4 \mathrm{~s}$.

\subsection{Modelling adsorption isotherms}

The loadings of each compound obtained from single (Section 4.1, Table 2) and multicomponent experiments (Sections 4.2.1 and 4.2.2, Table 3) were fitted with the Sips model isotherm (Eq. (1)). The single component isotherms for the linear nC5 and nC6 isomers in ZIF-8 fitted with the Sips model are shown in Fig. 4 by the continuous lines, where a reasonable agreement between model and experimental data is observed. Table 5 gives the parameters and the mean relative deviation between model and experimental data. The isotherms shown in Fig. 5 can be assumed as the representative of the system since they were

Table 3

Experimental conditions for multicomponent equimolar breakthrough curves of C5/C6 isomers in ZIF-8 and loadings.

\begin{tabular}{|c|c|c|c|c|c|c|c|c|c|c|c|c|c|}
\hline \multirow[t]{2}{*}{ Run } & \multirow[t]{2}{*}{ Temp. (K) } & \multirow{2}{*}{$\begin{array}{l}\text { Helium } \\
\text { flowrate } \\
\left(\mathrm{nm}^{3} \cdot \mathrm{s}^{-1}\right)\end{array}$} & \multirow{2}{*}{$\begin{array}{l}\text { Total C5/C6 } \\
\text { flowrate }^{*} \\
\left(\mu \mathrm{mol} \cdot \mathrm{s}^{-1}\right)\end{array}$} & \multirow{2}{*}{$\begin{array}{l}\text { Total } \mathrm{C} 5 / \mathrm{C} 6 \\
\text { pressure }(\mathrm{kPa})\end{array}$} & \multirow{2}{*}{$\begin{array}{l}\text { Mass of } \\
\text { adsorbent } \\
\left(\mathrm{kg} \times 10^{3}\right)\end{array}$} & \multicolumn{7}{|c|}{ Loading $\left(\mathrm{mol} \cdot \mathrm{kg}^{-1} \times 10^{2}\right)$} & \multirow{2}{*}{$\begin{array}{l}\text { Total } \\
\text { loading }\left(\mathrm{mol} \cdot \mathrm{kg}^{-1} \times 10^{2}\right)\end{array}$} \\
\hline & & & & & & iC5 & $\mathrm{nC5}$ & 22DMB & 23DMB & 3MP & $2 \mathrm{MP}$ & $\mathrm{nC6}$ & \\
\hline \multicolumn{14}{|c|}{ Septenary mixture } \\
\hline $2 \_1$ & 373 & 46.0 & 0.6751 & 25.0 & 1.796 & 5.63 & 42.9 & 0.568 & 1.66 & 12.1 & 20.0 & 110 & 193 \\
\hline $2 \_2$ & 423 & 46.0 & 0.6751 & 25.0 & 1.796 & 4.76 & 18.3 & 0.628 & 1.50 & 8.24 & 13.9 & 47.6 & 94.9 \\
\hline $2 \_3$ & 473 & 46.0 & 0.6751 & 25.0 & 1.796 & 3.64 & 6.57 & 0.585 & 1.36 & 4.21 & 6.95 & 14.2 & 37.5 \\
\hline \multicolumn{14}{|c|}{ Quinary mixture } \\
\hline $3 \_1$ & 373 & 46.0 & 0.6751 & 25.0 & 1.796 & 9.68 & - & 1.28 & 2.34 & 17.4 & 27.6 & - & 58.3 \\
\hline $3 \_2$ & 423 & 46.0 & 0.6751 & 25.0 & 1.796 & 6.74 & - & 0.855 & 1.84 & 11.1 & 16.4 & - & 36.9 \\
\hline 3_3 & 473 & 46.0 & 0.6751 & 25.0 & 1.796 & 5.42 & - & 0.691 & 1.72 & 6.32 & 10.6 & - & 24.8 \\
\hline
\end{tabular}

* STP: Standard temperature and pressure condition. 

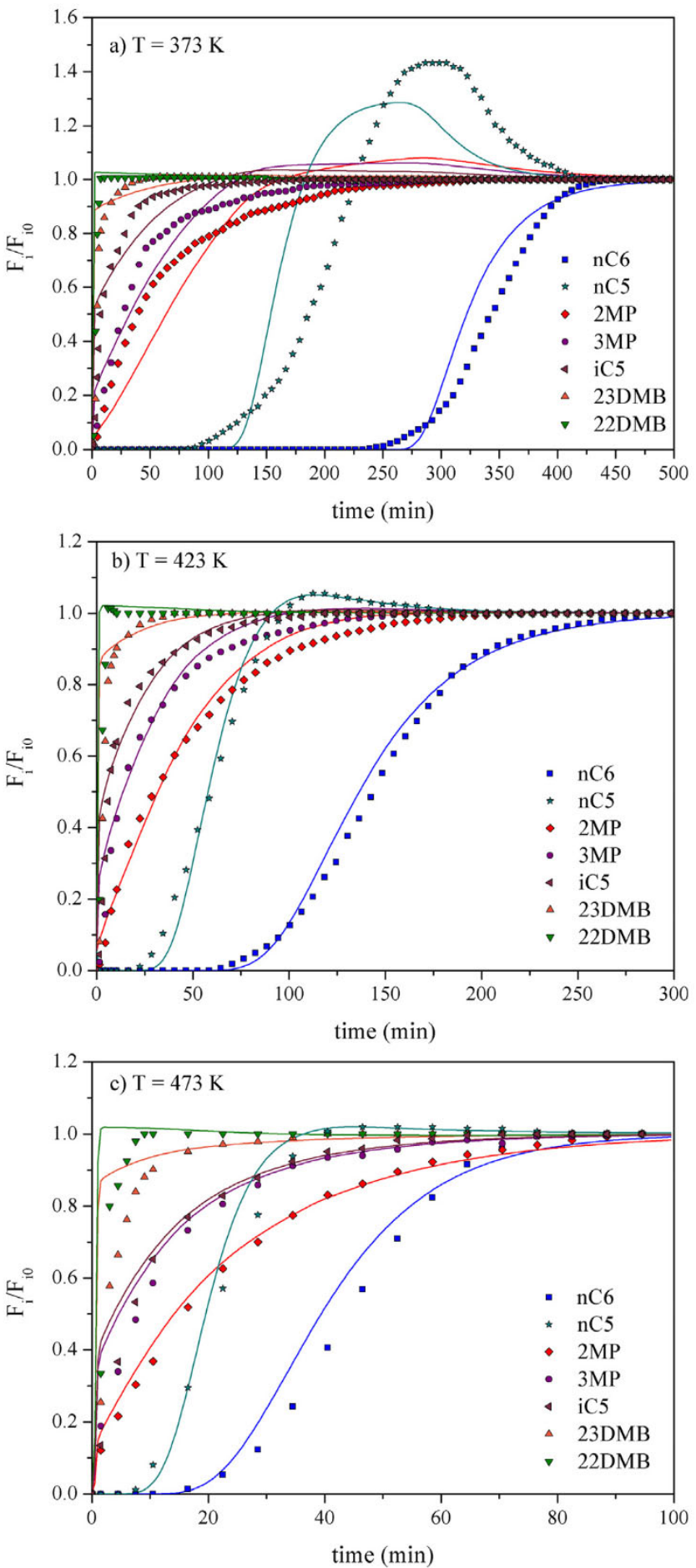

Fig. 5. Experimental and numerical breakthrough curves for a septenary equimolar mixture of pentane/hexane isomers in ZIF-8 at hydrocarbon total pressure of $25.0 \mathrm{kPa}$ : (a) $373 \mathrm{~K}$, (b) $423 \mathrm{~K}$ and (c) $473 \mathrm{~K}$. The continuous lines represent numerical simulations accounting for strong intracrystalline diffusional resistances for branched isomers $\left(\mathrm{D}_{\mathrm{nC} 6} / \mathrm{D}_{\mathrm{iC5}}, \mathrm{D}_{\mathrm{nC} 6} / \mathrm{D}_{2 \mathrm{MP}}, \mathrm{D}_{\mathrm{nC} 6} /\right.$ $\mathrm{D}_{3 \mathrm{MP}}=100, \mathrm{D}_{\mathrm{nC}} / \mathrm{D}_{23 \mathrm{DMB}}=150$, and $\left.\mathrm{D}_{\mathrm{nC} 6} / \mathrm{D}_{22 \mathrm{DMB}}=300\right)$.

obtained from breakthrough curves measured under equilibrium conditions. For the branched paraffins similar isotherms can be only obtained in a batch experimental system, since fixed bed adsorption is kinetically controlled. In such conditions we can only obtain pseudo adsorption equilibrium isotherms since as the residence time of the gas changes in the column the loading also changes as can be observed in Fig. 7 and Table 4.
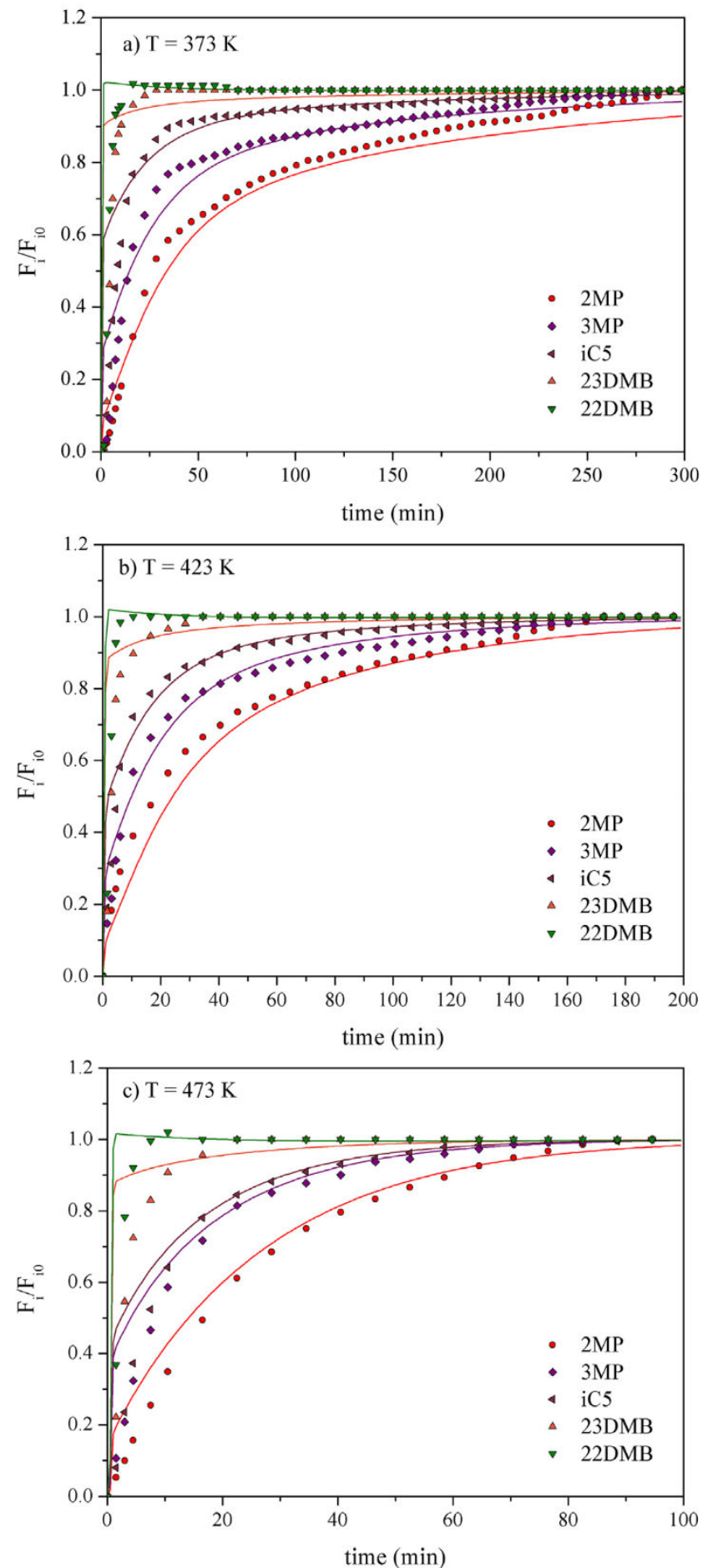

Fig. 6. Experimental and numerical breakthrough curves for a quinary equimolar mixture of branched pentane/hexane isomers in ZIF-8 at hydrocarbon total pressure of $25.0 \mathrm{kPa}$ : (a) $373 \mathrm{~K}$, (b) $423 \mathrm{~K}$ and (c) $473 \mathrm{~K}$. The continuous lines represent numerical simulations accounting for strong intracrystalline diffusional resistances for branched isomers $\left(\mathrm{D}_{\mathrm{nC} 6} / \mathrm{D}_{\mathrm{iC} 5}, \mathrm{D}_{\mathrm{nC} 6} / \mathrm{D}_{2 \mathrm{MP}}, \mathrm{D}_{\mathrm{nC} 6} /\right.$ $\mathrm{D}_{3 \mathrm{MP}}=100, \mathrm{D}_{\mathrm{nC} 6} / \mathrm{D}_{23 \mathrm{DMB}}=150$, and $\left.\mathrm{D}_{\mathrm{nC} 6} / \mathrm{D}_{22 \mathrm{DMB}}=300\right)$.

The parity plot with the loadings of model predictions plotted as a function of the experimental loadings is disclosed in Fig. 8 for the sorption of C5 and C6 isomers, showing the good ability of the Sips isotherm to represent such experimental data. 

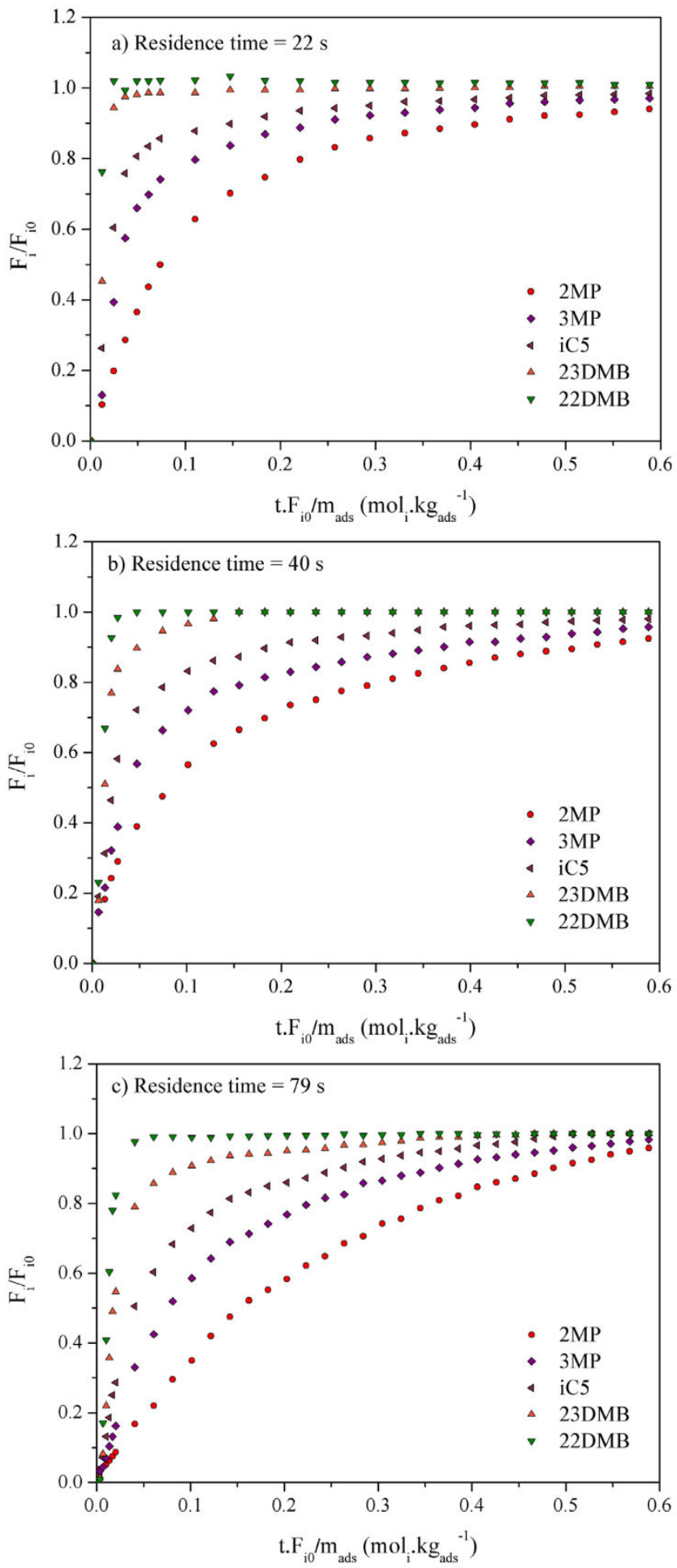

Fig. 7. Experimental breakthrough curves for adsorption of branched pentane/ hexane isomers in ZIF-8 measured at different residence times at $423 \mathrm{~K}$ and hydrocarbon total pressure of $25.0 \mathrm{kPa}$ : (a) $22 \mathrm{~s}$, (b) $40 \mathrm{~s}$, and (c) $79 \mathrm{~s}$.

\subsection{Numerical Modelling of breakthrough curves}

All experimental data, single (Section 4.1, Figs. 2 and 3) and multicomponent (Section 4.2, Figs. 5 and 6) breakthrough curves, were simulated with the dynamic adsorption model described in the Section 3.2. The results of the numerical simulations are represented in these figures by the continuous lines.

The simulations of single component breakthrough curves were conducted ensuring moderate diffusional limitations, being $\mathrm{D}_{\mathrm{c}} / \mathrm{r}_{\mathrm{c}}{ }^{2}$ equal to $0.002 \mathrm{~s}^{-1}$ at $373 \mathrm{~K}$ for both components nC5 and nC6. It can be seen that a good agreement between numerical and experimental data is observed, with the model capturing the shape of the breakthrough curves. All model parameters used for the simulations of pure component breakthrough curves are summarized in Appendix A.

For the multicomponent experiments, the simulations of the breakthrough curves were performed in two ways: (1) accounting for strong intracrystalline diffusional resistances (low diffusivities) for the branched isomers (iC5, 2MP, 3MP, 23DMB and 22DMB) Figs. 5 and 6, and (2) accounting for moderate diffusional resistances and equal for all isomers (high diffusivities), Figs. A2.1 and A2.2 of the Appendix A. In Figs. 5 and 6 , the differences between the diffusional resistances of the isomers in ZIF-8 is accounted by the ratios $\left(\mathrm{D}_{\mathrm{nC6}} / \mathrm{D}_{\mathrm{nC} 5}\right)$, $\left(\mathrm{D}_{\mathrm{nC} 6} / \mathrm{D}_{\mathrm{iC} 5}\right)$, $\left(\mathrm{D}_{\mathrm{nC} 6} / \mathrm{D}_{2 \mathrm{MP}}\right)$, $\left(\mathrm{D}_{\mathrm{nC} 6} / \mathrm{D}_{3 \mathrm{MP}}\right)$, $\left(\mathrm{D}_{\mathrm{nC} 6} / \mathrm{D}_{23 \mathrm{DMB}}\right)$, and $\left(\mathrm{D}_{\mathrm{nC} 6} / \mathrm{D}_{22 \mathrm{DMB}}\right)$, while in the Appendix $\mathrm{A}$ it can be seen the scenario when these ratios are all equal to 1 .

Table 6 summarizes the ratios of intracrystalline diffusivities used in the best fit to the experimental data. Equal diffusivities were found for linear nC5 and $\mathrm{nC6}\left(\mathrm{D}_{\mathrm{nC} 6} / \mathrm{D}_{\mathrm{nC5}}=1\right)$, being 100 times higher than for the mono-branched isomers $\left(\mathrm{D}_{\mathrm{nC} 6} / \mathrm{D}_{\mathrm{iC5}}=\mathrm{D}_{\mathrm{nC} 6} / \mathrm{D}_{2 \mathrm{MP}}=\mathrm{D}_{\mathrm{nC} 6} /\right.$ $\left.D_{3 \mathrm{MP}}=100\right), 150$ times higher than for the di-branched $23 \mathrm{DMB}\left(\mathrm{D}_{\mathrm{nC} 6} /\right.$ $\left.\mathrm{D}_{23 \mathrm{DMB}}=150\right)$ and 300 times higher than for the 22DMB $\left(\mathrm{D}_{\mathrm{nC} 6} /\right.$ $\left.\mathrm{D}_{22 \mathrm{DMB}}=300\right)$. The activation energy for diffusion $\left(-\Delta E_{D i}\right)$ for all C5/ C6 isomers, calculated from an Arrhenius law temperature dependence is of approximately $20 \mathrm{~kJ} \cdot \mathrm{mol}^{-1}$.

In Figs. 5 and 6 it is possible to see that the mathematical model qualitatively captures the profile of the breakthrough curves in the most of cases. However, the numerical model shows some difficulties to represent the multicomponent experimental data at the lowest temperature (Fig. 5a) where the interactions occurring inside the material due to competitive adsorption for preferential sites are higher, making difficult the match of the breakthrough curves profiles and overshoots. Probably, to better represent the breakthroughs at the lowest temperature, a robust adsorption model is necessary which will require a more detailed mass transfer mechanism, and refined thermodynamic model to account for the interactions between the adsorbed molecules. Nevertheless, the numerical simulations show that the simple LDF model and the empirical Sips isotherm can describe in a comprehensive manner the main features that governs the sorption phenomena of complex mixtures of C5/C6 isomers in ZIF-8, being a valuable tool to design cyclic processes. All model parameters used for the numerical simulations of multicomponent breakthrough curves are also summarized in Appendix A.

\section{Conclusions}

The adsorption dynamics of pentane nC5/iC5 and hexane nC6/ 2MP/3MP/23DMB/22DMB isomers in zeolitic imidazolate framework ZIF-8 was evaluated through a series of breakthrough experiments for single, quinary and septenary mixtures. Adsorption equilibrium isotherms for linear $\mathrm{nC5}$ and $\mathrm{nC} 6$ were measured from the single component breakthrough curves.

The screening studies based on the septenary mixture nC5/iC5/ nC6/2MP/3MP/23DMB/22DMB showed a complete separation of linear isomers nC5 and nC6 from the branched paraffins, especially at $373 \mathrm{~K}$. A partially separation between mono- and di-branched isomers is also achieved. When the temperature increases to $473 \mathrm{~K}$, the separation by classes is affected, with the nC5 isomer reaching the saturation even before the mono-branched ones.

The quinary experiments dealing with only branched isomers iC5/ $2 \mathrm{MP} / 3 \mathrm{MP} / 23 \mathrm{DMB} / 22 \mathrm{DMB}$ evidences the partial separation of monofrom di-branched isomers. It is also clear, that isńt feasible to obtain a pure fraction of di-branched isomers, since a contamination with the mono-branched alkanes will always occur. In addition, the experiments also evidence that the iC5 elutes from the column closer to the mono- 
Table 4

Experimental conditions and loadings for the multicomponent equimolar breakthrough curves of C5/C6 branched isomers in ZIF-8 at three different residence times.

\begin{tabular}{|c|c|c|c|c|c|c|c|c|c|c|c|c|}
\hline \multirow[t]{2}{*}{ RUN } & \multirow{2}{*}{$\begin{array}{l}\text { Residence } \\
\text { time (s) }\end{array}$} & \multirow[t]{2}{*}{ Temp. (K) } & \multirow{2}{*}{$\begin{array}{l}\text { Helium } \\
\text { flowrate } \\
\left(\mathrm{nm}^{3} \cdot \mathrm{s}^{-1}\right)\end{array}$} & \multirow{2}{*}{$\begin{array}{l}\text { Total C5/C6 } \\
\text { flowrate } \\
\left(\mu \mathrm{mol} \cdot \mathrm{s}^{-1}\right)\end{array}$} & \multirow{2}{*}{$\begin{array}{l}\text { Total } \mathrm{C} 5 / \mathrm{C} 6 \\
\text { pressure }(\mathrm{kPa})\end{array}$} & \multirow{2}{*}{$\begin{array}{l}\text { Mass of adsorbent } \\
\left(\mathrm{kg} \times 10^{3}\right)\end{array}$} & \multicolumn{5}{|c|}{ Loading $\left(\mathrm{mol} \cdot \mathrm{kg}^{-1} \times 10^{2}\right)$} & \multirow{2}{*}{$\begin{array}{l}\text { Total loading } \\
\left(\mathrm{mol} \cdot \mathrm{kg}^{-1} \times 10^{2}\right)\end{array}$} \\
\hline & & & & & & & iC5 & 22DMB & 23DMB & $3 \mathrm{MP}$ & $2 \mathrm{MP}$ & \\
\hline 4_1 & 22 & 423 & 83.3 & 1.223 & 25.0 & 1.796 & 5.45 & - & 1.21 & 8.95 & 14.8 & 30.4 \\
\hline 32 & 40 & 423 & 46.0 & 0.6751 & 25.0 & 1.796 & 6.74 & 0.855 & 1.84 & 11.1 & 16.4 & 36.9 \\
\hline $4 \_2$ & 79 & 423 & 23.0 & 0.3375 & 25.0 & 1.796 & 8.60 & 1.30 & 3.93 & 13.2 & 20.5 & 47.5 \\
\hline
\end{tabular}

* STP: Standard temperature and pressure condition.

branched hexanes, which can be a major drawback in view of the octane upgrading of gasoline, since this component has a high RON content of 92 compared to 73.4 and 74.5 for the 2MP and 3MP isomer, respectively.

It is also shown the effect of the residence time of the gas in the sorption dynamics of the branched paraffins, where at the lowest residence time of the gas studied (22 s) 22DMB and 23DMB are practically excluded from the fixed bed since they elute and saturate practically at the residence time. However, at a residence time of $79 \mathrm{~s} 23 \mathrm{DMB}$ saturates only after $0.4 \mathrm{~mol} \cdot \mathrm{kg}_{\mathrm{ads}}{ }^{-1}$ has been fed to the column.

The equilibrium data collected from breakthrough curves is well represented by the Sips isotherm. The fitted parameters were used in a mathematical model for fixed bed adsorption to simulate breakthrough experiments. From the numerical simulations, it was proved that the sorption of linear paraffins nC5 and nC6 is essentially equilibrium based, instead of the sorption of branched isomers which is kinetically driven. The best match of the breakthrough curves using a LDF kinetic model for mass transfer gives the following ratios of diffusivities: $\mathrm{D}_{\mathrm{nC} 6} /$ $\mathrm{D}_{\mathrm{nC5}}=1 ; \mathrm{D}_{\mathrm{nC} 6} / \mathrm{D}_{\mathrm{iC5}}=\mathrm{D}_{\mathrm{nC} 6} / \mathrm{D}_{2 \mathrm{MP}}=\mathrm{D}_{\mathrm{nC} 6} / \mathrm{D}_{3 \mathrm{MP}}=100, \mathrm{D}_{\mathrm{nC} 6} /$ $\mathrm{D}_{23 \mathrm{DMB}}=150$, and $\mathrm{D}_{\mathrm{nC} 6} / \mathrm{D}_{22 \mathrm{DMB}}=300$.

Finally, from the adsorption studies performed in this work we can conclude that, if experimental conditions are carefully setup, such as residence time and temperature, ZIF-8 is suitable to completely separate the linear nC5 and nC6 from its isomers and partially separate mono-branched from di-branched isomers.

\section{CRediT authorship contribution statement}

Adriano Henrique: Conceptualization, Methodology, Software, Validation, Formal analysis, Investigation, Writing - original draft, Writing - review \& editing. Alírio E. Rodrigues: Conceptualization, Writing - review \& editing, Supervision, Project administration. José

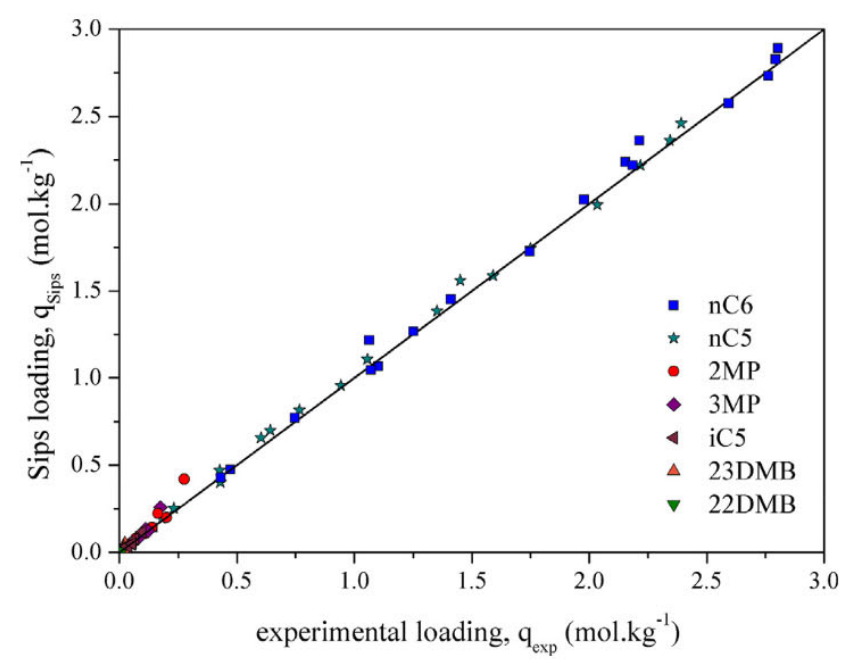

Fig. 8. Parity plot comparing loadings from experimental data and model predictions.

A.C. Silva: Conceptualization, Writing - review \& editing, Supervision, Project administration, Funding acquisition.

\section{Declaration of Competing Interest}

The authors declare that they have no known competing financial interests or personal relationships that could have appeared to influence the work reported in this paper.

Table 5

Sips isotherm parameters for the sorption of pentane/hexane isomers in ZIF-8 and mean relative deviation between model predictions and experimental data.

\begin{tabular}{|c|c|c|c|c|c|c|c|}
\hline \multirow[t]{2}{*}{ Sips Parameters } & \multicolumn{2}{|c|}{ Pentane isomers } & \multicolumn{5}{|c|}{ Hexane isomers (values taken from [33]) } \\
\hline & nC5 & iC5 & nC6 & $2 \mathrm{MP}$ & 3MP & 23DMB & 22DMB \\
\hline$q_{\max , l}\left(\mathrm{~mol} \cdot \mathrm{kg}^{-1}\right)$ & 3.15 & 1.10 & 3.30 & 2.50 & 2.30 & 0.950 & 0.750 \\
\hline$-\Delta H_{i}\left(\mathrm{~kJ} \cdot \mathrm{mol}^{-1}\right)$ & 34.4 & 22.3 & 41.6 & 25.2 & 23.0 & 21.0 & 17.8 \\
\hline$n_{l, 0}$ * & 1.21 & 1.29 & 1.33 & 1.31 & 1.28 & 1.09 & 0.928 \\
\hline$\alpha_{i}$ & 0.971 & 0.198 & 1.34 & 0.722 & 0.829 & 0.250 & 0.133 \\
\hline \multicolumn{8}{|l|}{ Temperature $373 \mathrm{~K}$} \\
\hline$n_{l, 1}$ & 1.21 & 1.29 & 1.33 & 1.31 & 1.28 & 1.09 & 0.928 \\
\hline$b_{l}\left(\mathrm{MPa}^{-1}\right)$ & 88.0 & 25.0 & 270 & 43.5 & 27.0 & 16.0 & 11.1 \\
\hline \multicolumn{8}{|l|}{ Temperature $423 \mathrm{~K}$} \\
\hline$n_{i, 2}$ & 1.06 & 1.25 & 1.10 & 1.18 & 1.14 & 1.06 & 0.914 \\
\hline$b_{l}\left(\mathrm{MPa}^{-1}\right)$ & 23.7 & 10.7 & 55.3 & 16.6 & 11.2 & 7.18 & 5.65 \\
\hline \multicolumn{8}{|l|}{ Temperature $473 \mathrm{~K}$} \\
\hline$n_{l, 3}$ & 0.968 & 1.22 & 0.97 & 1.09 & 1.04 & 1.03 & 0.904 \\
\hline$b_{l}\left(\mathrm{MPa}^{-1}\right)$ & 8.44 & 5.49 & 15.8 & 7.80 & 5.64 & 3.82 & 3.31 \\
\hline $\bar{\Delta} q$ & 0.0273 & & & & & & \\
\hline
\end{tabular}

\footnotetext{
* The reference temperature used was $T_{0}=373 \mathrm{~K}$.
} 
Table 6

Ratio of diffusivities for the sorption of pentane/ hexane isomers in ZIF-8.

\begin{tabular}{ll}
\hline Diffusivity ratios & \\
\hline$D_{n C 6} / r_{c}^{2}$ & $0.00200 \mathrm{~s}^{-1}$ \\
$D_{n C 6} / D_{n C 5}$ & 1.00 \\
$D_{n C 6} / D_{l C 5}$ & 100 \\
$D_{n C 6} / D_{2 M P}$ & 100 \\
$D_{n C 6} / D_{3 M P}$ & 100 \\
$D_{n C 6} / D_{23 D M B}$ & 150 \\
$D_{n C 6} / D_{22 D M B}$ & 300 \\
\hline
\end{tabular}

Values calculated at $373 \mathrm{~K}$

\section{Acknowledgments}

We acknowledge financial support from (1) Project ref POCI010145-FEDER-016517 (PTDC/QEQ-PRS/3599/2014) funded by FEDER through COMPETE2020 and FCT; (2) AIProcMat@N2020-Advanced Industrial Processes and Materials for a Sustainable Northern Region of Portugal 2020, with the reference NORTE-01-0145-FEDER-000006, supported by Norte Portugal Regional Operational Programme (NORTE 2020), under the Portugal 2020 Partnership Agreement, through the European Regional Development Fund (ERDF), and (3) by Project POCI-01-0145-FEDER006984-Associate Laboratory LSRE-LCM funded by ERDF through COMPETE2020, Programa Operacional Competitividade e Internacionalização (POCI), and by national funds through FCT - Fundação para a Ciência e a Tecnologia.

\section{Appendix A. Supplementary material}

Supplementary data to this article can be found online at https:// doi.org/10.1016/j.seppur.2019.116419.

\section{References}

[1] N. Morgan, A. Smallbone, A. Bhave, M. Kraft, R. Cracknell, G. Kalghatgi, Mapping surrogate gasoline compositions into RON/MON space, Combust. Flame 157 (2010) $1122-1131$.

[2] Z. Wang, H. Liu, R.D. Reitz, Knocking combustion in spark-ignition engines, Prog. Energy Combust. Sci. 61 (2017) 78-112.

[3] J.B. Heywood, Internal Combustion Engine Fundamentals, first ed., McGraw-Hil Education, 1988, p. 960.

[4] A. Demirbas, M.A. Balubaid, A.M. Basahel, W. Ahmad, M.H. Sheikh, M.A. Balubaid, A.M. Basahel, W. Ahmad, M.H. Sheikh, Octane rating of gasoline and octane booster additives, Pet. Sci. Technol. 33 (2015) 1190-1197.

[5] S.R. Naqvi, A. Bibi, M. Naqvi, N. Tayyaba, A.-S. Nizami, M. Rehan, M. Ayoub, New trends in improving gasoline quality and octane through naphtha isomerization: a short review, Appl. Petrochemical Res. 8 (2018) 131-139.

[6] J.G. Speight, The Chemistry and Technology of Petroleum, fifth ed., CRC Press, Boca Raton, 2014.

[7] S.A. Treese, P.R. Pujadó, D.S.J. Jones, Handbook of Petroleum Processing, second ed., Springer International Publishing, Switzerland, 2015.

[8] J.G. Speight, Handbook of Petroleum Refining, first ed., CRC Press, Boca Raton, 2016.

[9] T.C. Holcombe, n-paraffin - Isoparaffin Separation Process, US Patent, 4,176,053, 1979.

[10] T.C. Holcombe, Total Isomerization Process, US Patent, 4,210,771, 1980

[11] N.A. Cusher, UOP TIP and Once-Through Zeolitic Isomerization Processes, in: R.A. Meyers (Ed.), Handb. Pet. Refin. Process., third ed., McGraw-Hill Handbooks, New York, 2004, pp. 9.29-9.39.

[12] A. Minkkinen, L. Mank, S. Jullian, Process for the Isomerization of C5/C6 Normal Paraffins with Recycling of Normal Paraffins, US Patent, 5,233,120, 1993.

[13] A. Minkkinen, A. Deschamps, J.P. Cariou, Process for Isomerizing C5/C6 Normal Paraffins with Recycling Normal Paraffins and Methyl-Pentanes. U.S. Patent, 5,602,
291, 1997.

[14] B. Domergue, L. Watripont, Advanced solutions for paraffins isomerization, Natl Petrochemical Refiners Assoc. 2004, pp. 1-26.

[15] B. McCulloch, J.R. Lansbarkis, S. Raghuram, Extraction of Dimethyl Paraffins from Isomerates, US Patent, 5,107,052, 1992.

[16] H.W. Dandekar, G.A. Funk, R.D. Gillespie, H.A. Zinnen, C.P. McGonegal, M. Kojima, S.H. Hobbs, Process for Alkane Isomerization Using Reactive Chromatography, US Patent, 5,763,730, 1998

[17] H.W. Dandekar, G.A. Funk, H.A. Zinnen, Process for Separating and Recovering Multimethyl-Branched Alkanes, US Patent, 6,069,289, 2000.

[18] J.F.M. Denayer, R.A. Ocakoglu, J. Thybaut, G. Marin, P. Jacobs, J. Martens, G.V. Baron, n- and isoalkane Adsorption Mechanisms on Zeolite MCM-22, J. Phys. Chem. B 110 (2006) 8551-8558.

[19] J. Denayer, R. Ocakoglu, G. Baron, Method for Separating Hydrocarbons and Use of a Zeolite Therefor, US Patent, 7.435,865 B2, 2008.

[20] K. Huddersman, M. Klimczyk, Separation of branched hexane isomers using zeolite molecular sieves, AIChE J. 42 (1996) 405-408.

[21] K. Huddersman, M. Klimczyk, Separation of hexane isomers on zeolites mordenite and beta, J. Chem. Soc. - Faraday Trans. 92 (1996) 143-147.

[22] K.S. Park, Z. Ni, A.P. Cote, J.Y. Choi, R. Huang, F.J. Uribe-Romo, H.K. Chae, M. O'Keeffe, O.M. Yaghi, Exceptional chemical and thermal stability of zeolitic imidazolate frameworks, Proc. Natl. Acad. Sci. 103 (2006) 10186-10191.

[23] P.A.P. Mendes, A.E. Rodrigues, P. Horcajada, C. Serre, J.A.C. Silva, Single and multicomponent adsorption of hexane isomers in the microporous ZIF-8, Microporous Mesoporous Mater. 194 (2014) 146-156.

[24] M.T. Luebbers, T. Wu, L. Shen, R.I. Masel, Effects of molecular sieving and electrostatic enhancement in the adsorption of organic compounds on the zeolitic imidazolate framework ZIF-8, Langmuir 8 (2010) 15625-15633.

[25] L. Zhang, G. Qian, Z. Liu, Q. Cui, H. Wang, H. Yao, Adsorption and separation properties of n-pentane/isopentane on ZIF-8, Sep. Purif. Technol. 156 (2015) $472-479$.

[26] N. Chang, Z.Y. Gu, X.P. Yan, Zeolitic imidazolate framework-8 nanocrystal coated capillary for molecular sieving of branched alkanes from linear alkanes along with high-resolution chromatographic separation of linear alkanes, J. Am. Chem. Soc. 132 (2010) 13645-13647.

[27] D. Peralta, G. Chaplais, A. Simon-Masseron, K. Barthelet, G.D. Pirngruber, Separation of C6 Paraffins using zeolitic imidazolate frameworks: comparison with zeolite 5A, Ind. Eng. Chem. Res. 51 (2012) 4692-4702.

[28] D. Dubbeldam, R. Krishna, S. Calero, A.Ö. Yazaydin, Computer-assisted screening of ordered crystalline nanoporous adsorbents for separation of alkane isomers, Angew. Chemie - Int. Ed. 51 (2012) 11867-11871.

[29] Z.R. Herm, B.M. Wiers, J.A. Mason, J.M. Van Baten, M.R. Hudson, P. Zajdel, C.M. Brown, N. Masciocchi, R. Krishna, J.R. Long, Separation of hexane isomers in a metal-organic framework with triangular channels, Science 340 (2013) 960-964.

[30] A.F.P. Ferreira, M.C. Mittelmeijer-Hazeleger, M.A. Granato, V.F.D. Martins, A.E. Rodrigues, G. Rothenberg, Sieving di-branched from mono-branched and linear alkanes using ZIF-8: experimental proof and theoretical explanation, PCCP 15 (2013) 8795-8804.

[31] K. Zhang, R.P. Lively, C. Zhang, R.R. Chance, W.J. Koros, D.S. Sholl, S. Nair, Exploring the framework hydrophobicity and flexibility of ZIF-8: from biofuel recovery to hydrocarbon separations, J. Phys. Chem. Lett. 4 (2013) 3618-3622.

[32] L. Chen, S. Yuan, J.F. Qian, W. Fan, M.Y. He, Q. Chen, Z.H. Zhang, Effective ad sorption separation of n-hexane/2-methylpentane in facilely synthesized zeolitic imidazolate frameworks ZIF-8 and ZIF-69, Ind. Eng. Chem. Res. 55 (2016) 10751-10757.

[33] A. Henrique, A.E. Rodrigues, J.A.C. Silva, Separation of hexane isomers in ZIF-8 by fixed bed adsorption, Ind. Eng. Chem. Res. 58 (2019) 378-394.

[34] R. Sips, On the structure of a catalyst surface, J. Chem. Phys. 16 (1948) 490-495.

[35] R. Sips, On the structure of a catalyst surface. II, J. Chem. Phys. 18 (1950) 1024-1026.

[36] I. Langmuir, The adsorption of gases on plane surfaces of glass, mica and platinum, J. Am. Chem. Soc. 40 (1918) 1361-1403.

[37] H. Freundlich, Over the adsorption in solution, J. Phys. Chem. 57 (1906) 385-471.

[38] D.D. Do, Adsorption Analysis: Equilibria and Kinetics, Imperial College Press, London, 1998.

[39] W.E. Schiesser, G.W. Griffiths, A Compendium of Partial Differential Equation Models: Method of Lines Analysis with Matlab, Cambridge University Press, New York, 2009.

[40] W.E. Schiesser, wes1's Home Page. https://www.lehigh.edu/ wes1/.

[41] D.M. Ruthven, Principles of Adsorption and Adsorption Processes, John Wiley \& Sons, New York, 1984.

[42] M. Thommes, K. Kaneko, A.V. Neimark, J.P. Olivier, F. Rodriguez-Reinoso, J. Rouquerol, K.S.W. Sing, Physisorption of gases, with special reference to the evaluation of surface area and pore size distribution (IUPAC technical report), Pure Appl. Chem. 87 (2015) 1051-1069. 